\title{
Editorial \\ Neonatal Resuscitation in Children 2021: Focus on Training, Technology, and New Clinical Approaches
}

\author{
Daniele Trevisanuto ${ }^{1, *(\mathbb{D}}$, Viraraghavan Vadakkencherry Ramaswamy ${ }^{2}$ and Paolo Ernesto Villani ${ }^{3}$ \\ 1 Department of Woman's and Child's Health, University Hospital of Padua, 35128 Padua, Italy \\ 2 Department of Neonatology, Ankura Hospital for Women and Children, Hyderabad 500072, India; \\ 19.vira@gmail.com \\ 3 Department of Pediatrics, Fondazione Poliambulanza Istituto Ospedaliero, 25124 Brescia, Italy; \\ paolo.villani@poliambulanza.it \\ * Correspondence: daniele.trevisanuto@unipd.it; Tel.: +39-3406632734
}

Citation: Trevisanuto, D.; Ramaswamy, V.V.; Villani, P.E. Neonatal Resuscitation in Children 2021: Focus on Training, Technology, and New Clinical Approaches. Children 2022, 9, 175. https:// doi.org/10.3390/children9020175

Received: 4 January 2022

Accepted: 10 January 2022

Published: 1 February 2022

Publisher's Note: MDPI stays neutral with regard to jurisdictional claims in published maps and institutional affiliations.

Copyright: (C) 2022 by the authors. Licensee MDPI, Basel, Switzerland. This article is an open access article distributed under the terms and conditions of the Creative Commons Attribution (CC BY) license (https:// creativecommons.org/licenses/by/ $4.0 /)$.
Neonatal resuscitation remains a hot topic for pediatricians and neonatologists worldwide. Last year, several articles on different aspects related to neonatal resuscitation were published in the journal Children. The topics covered included staff training [1,2], technological aspects [3-6], and the investigation of "new" clinical interventions [7-12].

Amongst the various articles published last year in Children, that of Bettinger et al. reviewed the available literature on the topic of training opportunities during neonatal resuscitation [1]. The article's title, "Making every birth a learning event", mirrors the aim of the review, which was to explore the teaching opportunities that arise whenever a newborn is delivered. Bettinger et al. rightly point out that there are two crucial periods during which health personnel may be trained on neonatal resuscitation while attending a delivery. The first is during the delivery, at which time a trainee may gain expertise through various methods, including the traditional in-person teaching, remote coaching, or the use of automated guidance based on available software dedicated to neonatal resuscitation. The second training opportunity occurs after the delivery of the neonate, when the team has time to engage in a well-structured debriefing session conducted by an expert in the field. The review underlines the strengths, the limitations, and the gaps in knowledge of such educational approaches in relation to the setting and the available resources (high- vs. low-resource settings). Another interesting article by Haynes et al. from Norway suggests that low-dose, high-frequency in situ simulation improves staff performance [2]. These claims are based on previous reports that showed that low-dose, high-frequency training after participation in an initial course on neonatal resuscitation contributed to improving the initiation as well as timeliness of resuscitation procedures, which also translated into reduced 24-h neonatal mortality in low-resource settings $[13,14]$. Although these findings seem promising, the content to be repeated across recurrent training sessions as well as the ideal frequency of these sessions is yet to be established with good certainty.

Amongst the many articles published in Children, four of them describe emerging technologies for improving neonatal care at birth [3-6]. Two of them reported on new models of trolleys that could aid in the resuscitation of neonates with intact placental circulation at the bed side of the mother [3,4]. While one study was conducted in a high-resource setting, the other one described a low-cost trolley which could be used in low-resource settings. Though these new pieces of equipment offer all the required technical support to appropriately manage a neonate in need of resuscitation/stabilization at birth, the clinical impact of this approach needs to be established. Heart rate is the most important clinical indicator monitored during neonatal resuscitation [15]. Several modalities to monitor heart rate have been reported over the past few years [16]. In their clinical study, Rettedal et al. compared heart response from a dry-electrode ECG, the 3-lead ECG, and the pulse oximetry during newborn resuscitation [5]. The dry-electrode ECG was 
faster and more effective in providing a valuable HR than the 3-lead ECG and the pulse oximeter during the resuscitation of 48 neonates. Mannequin studies conducted in highand low-resource settings have shown that tools capable of providing ventilator feedback (i.e., mask leak, peak inspiratory pressure, and tidal volumes) improve the quality of positive pressure ventilation deployed by healthcare givers [17,18]. A study by Haynes et al compared ventilation parameters derived from a new, low-cost, high-fidelity simulator with those from real neonates in a group of experienced pediatricians [6]. Although the authors reported some limitations, the mannequin was able to simulate real life clinical situations. They concluded that this simulator could be an effective instrument for teaching positive pressure ventilation in neonates with mild as well as severe lung disease at birth. New technology that could aid in optimizing the healthcare providers' training and enhance neonatal monitoring immediately after delivery have increased exponentially over the last few years. Further research is needed to understand if these promising tools will impact the short and long-term clinical outcomes of neonates.

The ideal initial fraction of inspired oxygen $\left(\mathrm{FiO}_{2}\right)$ in preterm infants needing resuscitation at birth remains a matter of debate $[15,19]$. Amongst the published studies in Children in 2021, one human and one animal study have each assessed the impact of initial $\mathrm{FiO}_{2}$ or targeting different $\mathrm{SpO}_{2}$ ranges in two different clinical contexts $[7,8]$. The pilot study by Law et al. published in the journal compared two initial $\mathrm{FiO}_{2}$ values $(30 \%$ vs. $60 \%$ ) in 30 infants born at 23-28 weeks' gestation requiring delivery room resuscitation, with the aim of evaluating the feasibility of conducting such a trial [7]. Feasibility was defined by the authors in terms of achieving an adequate post-intervention consent rate and achieving a meaningful difference in the cumulative supplied oxygen in the first $5 \mathrm{~min}$. The results of this feasibility study are the basis for a larger randomized controlled trial (https: / / clinicaltrials.gov/ct2/show/NCT02858583, accessed on 2 January 2022). A preclinical study on a similar subject, but in a different context, assessed the impact of low (85-94\%) vs. high (95-99\%) $\mathrm{SpO}_{2}$ ranges on the ductal flow during and after resuscitation in lambs with meconium aspiration syndrome and persistent pulmonary hypertension [8]. In the immediate post-resuscitation phase, higher $\mathrm{SpO}_{2}$ targeting resulted in a faster reversal of the shunt to left-to-right direction across the patent ductus arteriosus, leading to improved pulmonary flow; however, this advantage was not maintained at $60 \mathrm{~min}$.

The aspects related to the outcome of peri-viable infants born at 22-25 weeks' gestational age was reported in a well-written review [9] and an observational single center cohort study from Taiwan [10]. The authors of the latter study reported a significant increase in the survival of peri-viable extremely low-gestational age infants after the implementation of the 2015 American Academy of Pediatrics Neonatal Resuscitation Program, which advocated a change in the threshold of viability from 23 weeks' to 22 weeks' gestation. However, data on long-term follow up of these high-risk infants are needed before drawing conclusive prognostic information.

Finally, two interesting articles have added information and offered hypotheses on patient management during the advanced phase of neonatal resuscitation. Kim et al. extensively reviewed the existing experimental and clinical evidence on chest compressions along with sustained inflation during cardiopulmonary resuscitation in neonates [11]. The findings suggest that this new approach is likely to be more effective than the currently used 3:1 compression to ventilation ratio in terms of a shorter time to the return of spontaneous circulation (ROSC), decreased mortality, and improvement in other respiratory and hemodynamic parameters. Results from a large multicenter randomized controlled trial (SURV1VE-trial-https:/ / clinicaltrials.gov/ct2/show/NCT02858583, accessed on 2 January 2022) are expected in 2024. Sankaran et al. compared the effect of two flush volumes (1 mL vs. $2.5 \mathrm{~mL}$ ) of normal saline in severely asphyxiated lambs immediately after epinephrine administration [12]. After the first dose of epinephrine, the ROSC was more frequently achieved in the group that received $2.5 \mathrm{~mL}$ compared to the group treated with $1.0 \mathrm{~mL}$ normal saline flush $(80 \%$ vs. $43 \% ; p=0.08)$. The median time to ROSC and cumula- 
tive epinephrine dose were similar between the two groups. Although interesting, these findings need to be confirmed in a well-designed randomized, controlled trial.

In conclusion, although there has been great progress over the last decade in our understanding of the pathophysiology of infants in need of resuscitation at birth, gaps in knowledge remain for a range of aspects related to neonatal resuscitation. The articles published in Children in 2021 have contributed immensely in furthering our knowledge in relation to neonatal resuscitation, and many of them could be the bases for future clinical trials.

Author Contributions: Conceptualization and writing—review and editing, D.T., V.V.R. and P.E.V. All authors have read and agreed to the published version of the manuscript.

Funding: This research received no external funding.

Conflicts of Interest: The authors declare no conflict of interest.

\section{Abbreviations}

ECG Electrocardiogram

$\mathrm{FiO}_{2} \quad$ Fraction of inspired oxygen

ROSC Return of spontaneous circulation

\section{References}

1. Bettinger, K.; Mafuta, E.; Mackay, A.; Bose, C.; Myklebust, H.; Haug, I.; Ishoso, D.; Patterson, J. Improving Newborn Resuscitation by Making Every Birth a Learning Event. Children 2021, 8, 1194. [CrossRef] [PubMed]

2. Haynes, J.; Rettedal, S.; Perlman, J.; Ersdal, H. A Randomised Controlled Study of Low-Dose High-Frequency In-Situ Simulation Training to Improve Newborn Resuscitation. Children 2021, 8, 1115. [CrossRef] [PubMed]

3. Ditai, J.; Barry, A.; Burgoine, K.; Mbonye, A.K.; Wandabwa, J.N.; Watt, P.; Weeks, A.D. The BabySaver: Design of a New Device for Neonatal Resuscitation at Birth with Intact Placental Circulation. Children 2021, 8, 526. [CrossRef] [PubMed]

4. Joshi, N.S.; Padua, K.; Sherman, J.; Schwandt, D.; Sie, L.; Gupta, A.; Halamek, L.P.; Lee, H.C. A Feasibility Study of a Novel Delayed Cord Clamping Cart. Children 2021, 8, 357. [CrossRef] [PubMed]

5. Rettedal, S.; Eilevstjønn, J.; Kibsgaard, A.; Kvaløy, J.T.; Ersdal, H. Comparison of Heart Rate Feedback from Dry-Electrode ECG, 3-Lead ECG, and Pulse Oximetry during Newborn Resuscitation. Children 2021, 8, 1092. [CrossRef] [PubMed]

6. Haynes, J.; Bjorland, P.; Gomo, Ø.; Ushakova, A.; Rettedal, S.; Perlman, J.; Ersdal, H. Novel Neonatal Simulator Provides High-Fidelity Ventilation Training Comparable to Real-Life Newborn Ventilation. Children 2021, 8, 940. [CrossRef]

7. Law, B.H.Y.; Asztalos, E.; Finer, N.N.; Yaskina, M.; Vento, M.; Tarnow-Mordi, W.; Shah, P.S.; Schmölzer, G.M. Higher versus Lower Oxygen Concentration during Respiratory Support in the Delivery Room in Extremely Preterm Infants: A Pilot Feasibility Study. Children 2021, 8, 942. [CrossRef] [PubMed]

8. Lesneski, A.L.; Vali, P.; Hardie, M.E.; Lakshminrusimha, S.; Sankaran, D. Randomized Trial of Oxygen Saturation Targets during and after Resuscitation and Reversal of Ductal Flow in an Ovine Model of Meconium Aspiration and Pulmonary Hypertension. Children 2021, 8, 594. [CrossRef]

9. Schwaberger, B.; Urlesberger, B.; Schmölzer, G.M. Delivery Room Care for Premature Infants Born after Less than 25 Weeks' Gestation-A Narrative Review. Children 2021, 8, 882. [CrossRef]

10. Chen, Y.-J.; Yu, W.-H.; Chen, L.-W.; Huang, C.-C.; Kang, L.; Lin, H.-S.; Iwata, O.; Kato, S.; Hussein, M.H.; Lin, Y.-C. Improved Survival of Periviable Infants after Alteration of the Threshold of Viability by the Neonatal Resuscitation Program 2015. Children 2021, 8, 23. [CrossRef]

11. Kim, S.Y.; Shim, G.-H.; Schmölzer, G.M. Is Chest Compression Superimposed with Sustained Inflation during Cardiopulmonary Resuscitation an Alternative to 3:1 Compression to Ventilation Ratio in Newborn Infants? Children 2021, 8, 97. [CrossRef]

12. Sankaran, D.; Vali, P.; Chandrasekharan, P.; Chen, P.; Gugino, S.F.; Koenigsknecht, C.; Helman, J.; Nair, J.; Mathew, B.; Rawat, M.; et al. Effect of a Larger Flush Volume on Bioavailability and Efficacy of Umbilical Venous Epinephrine during Neonatal Resuscitation in Ovine Asphyxial Arrest. Children 2021, 8, 464. [CrossRef] [PubMed]

13. Mduma, E.; Ersdal, H.; Svensen, E.; Kidanto, H.L.; Auestad, B.; Perlman, J. Frequent brief on-site simulation training and reduction in 24-h neonatal mortality-An educational intervention study. Resuscitation 2015, 93, 1-7. [CrossRef] [PubMed]

14. Cavicchiolo, M.E.; Cavallin, F.; Bertuola, F.; Pizzol, D.; Segafredo, G.; Manzungu Wingi, O.; Da Dalt, L.; Putoto, G.; Trevisanuto, D. Effect of a Low-Dose/High-Frequency Training on Real-Life Neonatal Resuscitation in a Low-Resource Setting. Neonatology 2018, 114, 294-302. [CrossRef] [PubMed]

15. Madar, J.; Roehr, C.C.; Ainsworth, S.; Ersdal, H.; Morley, C.; Rüdiger, M.; Skåre, C.; Szczapa, T.; Te Pas, A.; Trevisanuto, D.; et al. European Resuscitation Council Guidelines 2021: Newborn resuscitation and support of transition of infants at birth. Resuscitation 2021, 161, 291-326. [CrossRef] [PubMed] 
16. Johnson, P.A.; Cheung, P.Y.; Lee, T.F.; O’Reilly, M.; Schmölzer, G.M. Novel technologies for heart rate assessment during neonatal resuscitation at birth-A systematic review. Resuscitation 2019, 143, 196-207. [CrossRef] [PubMed]

17. Van Vonderen, J.J.; Witlox, R.S.; Kraaij, S.; te Pas, A.B. Two-minute training for improving neonatal bag and mask ventilation. PLoS ONE 2014, 9, e109049. [CrossRef] [PubMed]

18. Mazza, A.; Cavallin, F.; Cappellari, A.; Divisic, A.; Grbin, I.; Akakpo, J.; Moukaila, A.R.; Trevisanuto, D. Effect of a short training on neonatal face-mask ventilation performance in a low resource setting. PLoS ONE 2017, 12, e0186731. [CrossRef]

19. Welsford, M.; Nishiyama, C.; Shortt, C.; Weiner, G.; Roehr, C.C.; Isayama, T.; Dawson, J.A.; Wyckoff, M.H.; Rabi, Y.; International Liaison Committee on Resuscitation Neonatal Life Support Task Force. Initial Oxygen Use for Preterm Newborn Resuscitation: A Systematic Review with Meta-analysis. Pediatrics 2019, 143, e20181828. [CrossRef] 